Yakobson R.O. Lingvistika i poetika [Linguistics and Poetics]. Strukturalizm : «za» $i$ «protiv» [Structuralism: «For» and «Against»]. Moskva, 1975.

Chandler D. Semiotics: the Basics. New York, 2007.

Forster E.M. Aspects of the Novel. New York, 1927.

Habbeger A. My Wars Are Laid Away in Books: The Life of Emily Dickinson. New York, 2002.

Vanderslice J. Dickinson's 'Behind Me-Dips Eternity'. Explicator. 2000. No. 4.

\title{
List of sources
}

Gavrilov A.G. Perevodya Emili Dikinson (iz dnevnikov) [Translations of Emily Dickinson (from diaries)]. URL: https://biography.wikireading.ru/36617

Evangelie ot Matfeya, ot Luki, ot Marka, ot Ioanna [Gospel from Mathew, Luke, Mark, John]. URL: http://bibliya-online.ru/chitat-evangelie-ot-marka-onlayn/

Markova V. Emili Dikinson [Emily Dickinson]. URL: http://www.uspoetry.ru/poets/7/poems

Postnikov V. Emily Dickinson - Emili Dikinson [Emily Dickinson - Emily Dickinson]. URL: https://www.stihi.ru/avtor/transpoetry

Dickinson E. The Complete Poems of Emily Dickinson. Boston, 1955.

Dickinson, E. The Complete Poems. URL: https://www.bartleby.com/113/

English Oxford Living Dictionaries. [Электронный pecypc]. URL: https://www.lexico.com/en/definition/ability

\section{ДИСКУРС ЛЮБВИ В ХУДОЖЕСТВЕННОЙ ЛИТЕРАТУРЕ (НА МАТЕРИАЛЕ РОМАНА ЭРИКА ШМИТТА «ПОПУГАИ С ПЛОЩАДИ АРЕЦЦО»)}

\section{Е.А. Вдовиченко, Г.И. Лушникова}

Ключевые слова: дискурс, текст, художественная литература, любовный дискурс, Эрих Шмитт.

Keywords: discourse, text, fiction text, discourse of love, E.E. Schmitt.

\section{DOI 10.14258/filichel(2019)3-10}

Существует достаточно много работ, посвященных изучению различных видов дискурса (политического, медицинского, педагогического, экологического, художественного, интернет-дискурса и других). В каждой работе понятие «дискурс» трактуется по-разному в зависимости от теоретических установок того или иного автора.

У. Чейф писал, что «дискурс многосторонен, и достаточно очевидна ограниченность любых попыток отразить его моделирование, 
сведя дискурс к одному или двум измерениям» [цит. по Асратян, 2015, c. 31]. Дискурс определяют как вид речевой коммуникации (Ю. Хабермас, Г. Почепцов) и как текст (В. Борботько, В. Карасик, А. Кибрик).

По мнению Т.Ф. ван Дейка, дискурс - это существенная составляющая социокультурного взаимодействия, характерные черты которого - интересы, цели и стили [Дейк, 1989, с. 53].

М. Фуко считал, что дискурс - сложный и относительно устойчивый способ структурирования, который обладает значимостью для определенного коллектива; то есть тексты, которые содержат разделяемые убеждения, вызываемые или усиливаемые ими, иными словами, тексты, которые предполагают позицию в дискурсном поле. Корпус текстов при этом рассматривается не сам по себе, а как одна из частей признанного социального института, который определяет для данной социальной, экономической, географической или лингвистической сферы условия действия актов высказывания [Серио, 2001, c. 551]. То есть под дискурсом понимается любой текст с учетом его коммуникативных и экстралингвистических характеристик [Асратян, 2015, с. 31]. Данную идею подтверждает и Е.В. Гаврилова, подчеркивая, что «художественный текст удовлетворяет всем признакам: он отражает менталитет и культуру общества, в рамках которого создавалось литературное произведение, и обусловлен ситуацией и контекстом своего функционирования; он интерактивен и внешне (взаимодействие автора и читателя), и внутренне (взаимодействие персонажей); он преследует определенную цель (эстетического воздействия, убеждения, развлечения)» [Гаврилова, 2007, c. 113].

Следовательно, правомерно говорить, что художественный дискурс как разновидность бытийного общения представляет собой развернутый, предельно насыщенный смыслами полилог автора, читателя и текста, выявляющий взаимодействие авторских интенций, сложного комплекса возможных реакций читателя и текста [Олизько, 2011, с. 165-166]. Художественный дискурс неоднороден, он состоит из поддискурсов, которые создают этот причудливый многоцветный ковер всего произведения [Асратян, 2015, с. 32].

В данной работе представлен анализ дискурса любви в романе Эрика Шмитта «Попугаи с площади Ареццо». Под дискурсом любви вслед за О.А. Велюго мы понимаем «художественное произведение целиком либо совокупность художественных произведений, в которых любовный дискурс персонажей и / или автора значим для понимания идейного содержания. Дискурс любви - речь 
влюбленного от лица персонажа, рассказчика или автора, понимаемая в аспекте диалога с другими в связи с экстралингвистическим контекстом» [Велюго, 2016, с. 10].

Следовательно, в ходе изучения дискурса любви в романе Эрика Шмитта мы должны учесть, что события происходят в XXI веке в Бельгии, в коммуне Усть. Эрик Шмитт является современным французским философом, писателем и кинорежиссером, а также одним из самых успешных европейских драматургов. В своем новом романе «Попугаи с площади Ареццо» он задает вопрос самому себе и, соответственно, читателям: что есть любовь? - но не дает однозначного ответа. Это вопрос о сущности любви в браке, о природе взаимоотношений между мужчиной и женщиной, о моральных ценностях, верности и ревности, о межличностных и внутренних конфликтах. Эти проблемы рассмотрены в плюралистическом ключе.

В данном произведении показаны любовные отношения 37 героев, живущих по соседству на площади Ареццо. Они связаны между собой любовными, семейными, дружескими отношениями. Описание их отношений, речевые акты, выражающие чувство любви, и авторская интерпретация представляют собой дискурс любви.

Поражает не только количество персонажей в одном романе, но и их разнообразие, они отличаются по социальному статусу, возрасту, темпераменту, психологическим характеристикам. Такое разнообразие дает возможность выделить разноаспектные черты современного дискурса любви на материале данного произведения Эрика Шмитта. Многообразие является главной особенностью этого романа, что также является неотъемлемой чертой постмодернистского направления. В романе противопоставляется дискурс романтической любви любовному дискурсу постмодернизма.

Все представленные пары в произведении можно поделить на две большие группы: те, которые состоят в браке, и те, которые не состоят. Рассмотрим каждую из групп.

В первую группу входят семьи, которые отличаются между собой возрастом и социальным статусом. Первая пара, с описания которой начинается роман, это образованная состоятельная семья без общих детей. Захарий Бидерман свой брак характеризует как жизнеспособный coю3, в котором партнеры не мешают друг другу жить: «C'est mon troisième marriage. Aussi le troisième de Rose. Autant dire que ni elle ni moi n'avions l'intention de nous fourvoyer <...> On n'apprend que ses erreurs. Cette fois, il s'agit d'une saine et bonne alliance» (Schmitt, 2013, 
с. 13)․ ‘Это мой третий брак. И третий брак Розы. Понятно, что ни она, ни я не хотим морочить друг другу голову. <..> Он хлопнул себя по ляжке. <..> Учимся мы только на своих ошибках. На сей раз заключен жизнеспособный союз' (Кончаловская, URL). Бидерман является хозяином дома, у него вся жизнь проходит согласно расписанию: «Si personne, même Rose, ne pénétrait dans le bureau de Zachary Bidermannsana l'appeler au préalable, lui débarquait partout sitôt qu'il le souhaitait. Rose s'en accomodait, estimant que la disponibilité appartenait à son role d'épouse aimante, alertée que, de toute façon, le "n'importe quelle heure" tombait toujours à onze heures" (Schmitt, 2013, с. 16-17). 'Если никому, и даже Розе, не позволялось входить в кабинет Захария Бидермана без вызова, сам он имел право, не спрашивая открывать любую дверь своего дома. Роза смирилась, полагая, что доступность является неотъемлемым признаком амплуа любящей супруги, и ее приятно возбуждало, что «неурочный час» всегда приходился на одно и то же время - одиннадцать часов утра (Кончаловская, URL). Разговоры между Бидерманом и его женой, Розой, были всегда на общеполитические темы и никогда не касались бывшей и настоящей личной совместной жизни: «Jamais ils ne nourrissaient leurs échanges de sujets particuliers, ils s'en tenaient aux sujets généraux: des enfants de Rose avec ses maris précédents, ils ne parlaient pas; des enfants de Zachary avec ses épouses antérieures, ils ne parlaient pas non plus, préférant deviser comme deux étudiants de sciences politiques, délestés des tourments familiaux, des avanies domestiques. La santé de ce jeune couple de sexagénaires tenait à l'amnésie sur leurs mariages et sur leurs consequences» (Schmitt, 2013, с. 17). 'Они никогда не заговаривали о личном, ни о детях Розы и ее предыдущих мужьях, ни о детях Захария и его бывших женах, предпочитая по-студенчески беседовать на общеполитические темы, свободные от семейных забот и домашних дрязг. Счастье этой четь шестидесятилетних молодоженов покоилось на забвении прошльх браков $u$ ux последствий' (Кончаловская, URL).

Согласно сказанному выше, данную супружескую пару можно охарактеризовать следующим образом:

- спокойная уравновешенная жизнь согласно расписанию;

- мужчина - хозяин дома;

- общение, не касающееся предыдущей личной жизни супругов.

\footnotetext{
${ }^{1}$ Здесь и далее в круглых скобках даны ссылки на тексты из списка источников, приведенного в конце статьи.
} 
Вторая пара - Франсуа-Максим и Северина - молодая состоятельная семья с тремя детьми. Окружающим людям кажется, что это жизнерадостная, счастливая семья, в которой мать следит за домом, ухаживает за детьми и мужем, отец отвозит их в школу, вечером все собираются за столом, и перед сном с каждым ребенком отец обсуждает, как прошел день. Но, с другой стороны, Северина очень несчастна, ее никто не понимает, и она не испытывает никаких чувств по отношению к своему мужу и детям: «Parce qu'elle ne ressentait rien. Ou pas grand-chose. Elle s'estimait incapable d'un geste décisif envers quiconque et demeurait stupéfaite que personne n'en ê̂t pris conscience. Si François-Maxime était devenu son mari, cétait parce qu'il l'avait propose: elle n'avait fait qu'y consenter <...> Son role de mère, elle se contentait de l'assumer, elle accomplissait son devoir et délivrait avec minutie les signes de l'amour. Il ne s'agissait pas seulement de passivité, mais de vide intérieur» (Schmitt, 2013, с. 197-198). 'Потому что она ничего не чувствовала. Или почти ничего. Неспособная на решительное действие в отношении кого бы то ни было, она удивилась, что другим это непонятно. Если Франсуа-Максим стал ее мужем, то лишь потому, что он это предложил, и она согласилась... Что касается роли матери, она лишь примирилась со свочм долгом и тщательно исполняла ритуаль материнской любви. И дело было не в пассивности, a во внутренней пустоте' (Кончаловская, URL). Даже ее муж, Франсуа-Максим, не замечает ее безразличия к жизни. Например, когда он сделал ей подарок - дорогую сумку, он был так счастлив от своего поступка, что не увидел безразличие жены: «après avoir offert son orésent, François-Maxime s'était montré d'une humeur plus allègre et plus enjouée que d'ordinaire. Bien qu'elle ne fût pas heureuse, elle les rendait heureux» (Schmitt, 2013, c. 198). 'Вручив свой подарок, ФрансуаМаксим развеселился и был игривее обычного. Хоть она и не была счастлива, она делала их счастливыми' (Кончаловская, URL). Также следует отметить, что Франсуа-Максим любит свою жену, пытается ее радовать, делает ей разные сюрпризы.

В представленном дискурсе любви данная супружеская пара имеет такие характерные черты:

- $\quad$ молодая пара с детьми;

- кажущееся взаимопонимание супругов;

- жизнь по шаблону счастливой семьи.

Следующая пара, которую мы рассмотрим, это семейная пара средних лет, в которой один из супругов является известной творческой личностью, писателем. Батист верен своей жене, Жозефине: «Maintenant, devenu un parfait époux, il ne touchait pas d'autre 
femme que Joséphine» (Schmitt, 2013, c. 33). 'Теперь он стал безупречным супругом и не прикасался ни к одной женщине, кроме Жозефинь' ' (Кончаловская, URL). С первого дня их встречи он сильно увлекся своей женой, которая являлась полной его противоположностью: «Dès le premier jour, il s'était entice de cette personnalité forte, fougueuse, au caractère abrupt. En une seconde, Joséphine diagnostiquait un problem ou un comportement quand Batiste devait délibérer anfin d'arriver à un résultat identique. Elle avançait par intuition, lui par réflexion. Alors qu'il multipliait les raisonnements et les references avant de produire un jugement critique, il la voyait atteindre au but en un éclair, come ilome par la grâce. Tandis qu'il représentait l'intellectuel tête de classe, bête à concours, bardé de diplômes, Joséphine, laquelle avait évité de passer le bac, lui semblait plus intelligente que luì" (Schmitt, 2013, c. 189). 'С первого дня их знакомства он увлекся этой сильной личностью с порывистыл, резким характером. Жозефина в одну секунду диагностировала ситуацию или чье-то поведение, когда Батисту требовалось размышиение, чтобы прийти $к$ сходному выводу. Она действовала интуитивно, он - рассудочно. Если он множил размышления и объяснения, прежде чем сделать вывод, он видел, что она достигает иели молниеносно, будто озарением. Если он был зубрилой, отличником, дипломированным интеллектуалом, то Жозефина, не удосужившаяся сдать и школьных выпускных экзаменов, казалась ему умнее его' (Кончаловская, URL). Как отмечает сам Батист, его жена была необыкновенной женщиной, она в любой момент могла сделать то, что от нее совсем не ожидали окружающие ее люди: «Si elle s'avérait unique, elle ne le devait à aucune stratégie, aucune culture; consciente de sa difference, elle était elle, rien qu'elle, intense, incapable de faire autrement $<\ldots>$ Avec Joséphine, Baptiste ne $s$ 'ennuyait jamais car il ignorait toujours comment elle allait se comporter, son ascendant tenant à son imprévisibilité» (Schmitt, 2013, c. 189-190). 'Своей уникальностью она не была обязана никакой методике, никакому образованию; сознавая свою особость, она была самой собой, только собой, яркая, неспособная поступать иначе 〈...> C Жозефиной Батисту не бывало скучно, поскольку он никогда не знал, как она поступит; ее привлекательность обусловливалась непредсказуемостью' (Кончаловская, URL). Жозефина для него не просто женщина, а все типы женщин объединенные в одну: «ти n'es pas une femme, plutôt un catalogue de femmes»' (Schmitt, 2013, c. 190). 'Tbl не женщина, а каталог женщин' (Кончаловская, URL). Что касается Жозефины, то она тоже очень сильно любит своего мужа, о чем ярко свидетельствует следующее высказывание: «ilom l'homme de ma vie 
parce que je veux vieillir avec toi <...> ilom l'homme de ma vie parce que tu les dépasses et les templaces tous»' (Schmitt, 2013, с. 185). 'Tы мужчина моей жизни, потому что я хочу стареть с тобой <...> Ть мужчина моей жизни, потому что ты превосходишь и заменяешь всех остальныхх' (Кончаловская, URL).

Согласно дискурсу любви Батиста и Жозефины выделяются следующие особенности семейной пары средних лет, не имеющей детей, когда один из супругов является известным человеком:

- $\quad$ противопоставление характеров супругов;

- увлечение супругов друг другом;

- взаимопонимание супругов.

Выше были рассмотрены три обеспеченных семьи, в которых складываются разные любовные отношения. Теперь изучим дискурс любви менее обеспеченной семейной пары, не имеющей детей, которая является единственной в данном романе. Орион и Ксавьера - обычные владельцы маленького цветочного магазина. Орион имеет заболевание Альцгеймера, поэтому за магазином и за ним следит его жена, Ксавьера. Она не любит готовить, следовательно, муж плохо питается. В целом, все домашние дела выполняет Орион, как домашний раб, взамен на затраченные силы и заботу своей жены: «elle détestait cuisine et Orion mangeait aussi peu qu'un alcoolique $\langle. . .>$ dont elle avait la charge, une sorte d'esclave familial qui devait travailler beaucoup pour justifier les efforts qu'il lui coûtait» (Schmitt, 2013, c. 137). 'Она ненавидела кухарить, и Орион жил на голодном пайке <...> о котором ей приходилось заботиться, и домашним рабом, который должен был много трудиться, чтобы оправдать затраченные на него усилия' (Кончаловская, URL). Ксавьера никогда не слушает своего мужа Ориона. Она считает, что он не может сказать что-либо стоящего внимания. Его разговоры для нее как фон на заднем плане во время дел по дому: "Elle n'écoutait jamais ce qu'il disait; convaincue que la plupart du temps ce babil ne véhiculait aucune idée intéressante, elle y accordait moins d'attention qu'à un jappement” (Schmitt, 2013, c. 138). 'Она никогда не обращуала внимания на его болтовню, полагая, что в ней не может содержаться ничего достойного внимания, и прислушивалась $\kappa$ ней не больше, чем к птичьему щебету' (Кончаловская, URL). Следует отметить, что они являются противоположностями друг другу: чтобы Ксавьера ни делала, Орион делает все по-другому: «<...> plus elle se montrait méfiante, plus il se montrait intrépide; plus elle critiquait les gens, plus il les louait» (Schmitt, 2013, с. 307). '〈...> чем осмотрительнее она становилась, тем он был бесстрашнее, чем больше она критиковала людей, тем больше он их расхваливал' 
(Кончаловская, URL). Ксавьера очень устала от такой совместной жизни, ей ничего в ней не нравится, но, несмотря на это, она пытается сохранить союз: "Elle n'aimait donc plus rien de son couple, ni elle ni lui, et cependant elle s'efforçait de le maintenir en survie» (Schmitt, 2013, c. 307-308). 'И ей теперь уже ничего не нравилось в их совместной жизни: ни она сама, ни муж, но все же она пьталась ее сохранить' (Кончаловская, URL).

В представленном описании пары мы видим, что в менее обеспеченной семье без общих детей, в которой один из супругов имеет сильное заболевание, прослеживаются следующие черты:

- $\quad$ женщина - руководитель всех финансовых дел;

- мужчина, прислуживающий по дому;

- супруга, уставшая от жизни;

- супруги меняются общепринятыми ролями: жена делает все за мужа, а муж - за жену.

При изучении четырех семейных пар мы нигде не упомянули такую тему, как измена. Теперь подробно остановимся на этом. В каждой из представленных семей есть хоть один из супругов, который изменяет партнеру и считает это нормой, что является второй особенностью проявления современного дискурса любви в романе Эрика Шмитта и противопоставляется романтическому дискурсу любви.

Например, в пожилой семейной паре политиков муж, хозяин дома, изменяет своей жене Розе, обращаясь к услугам девушек по вызову, и при этом еще восхваляет их: “Vive les épouses et vive les putes! Ce sont les seules femmes qui se contrôlent» (Schmitt, 2013, c. 21). 'Дa здравствуют жены и илюхи! Только эти женщчины держат себя в руках' (Кончаловская, URL). Во время измены он ощущает власть над девушкой, управляет ею, держит под контролем.

Во второй семейной паре, которая кажется всем счастливой, к измене прибегают оба супруга, жена Северина и ее муж ФрансуаМаксим. Следует отметить, что в предыдущей паре Захарий Бидерман изменял с многочисленными представительницами противоположного пола, в то время как Северина изменяет с постоянной партнершей, а Франсуа-Максим с разными неизвестными для него партнерами. Франсуа-Максим отзывается об измене как о каком-то экстремальном, рискованном деле, которое поднимает ему настроение на весь день: «il adorait la tension qu'adjoignait le danger: non seulement il se livrait àdes amours interdites, mais il s'y adonnait en plein air, ce qui ajoutait le ilomet de la transgression <...> François-Maxime jubila: il allait passer une bonne journée» (Schmitt, 2013, c. 69-70). 'Он обожал напряжение от 
опасности: он не только предавался запретной любви, но делал это с риском быть застигнутым <...> Франсуа-Максим блаженствовал: день выдался удачныци' (Кончаловская, URL).

Северина, его жена, изменяет с Ксавьерой, которая тоже изменяет своему больному мужу, Ориону. Они обе прибегают к измене, потому что хотят дарить и принимать любовь: «<...> ilo avaient besoin d'amour - de l'offrir et de le recevoir» (Schmitt, 2013, c. 305). '<...> им хотелось не заниматься любовью, им хотелось самой любви - дарить ее и получать в ответ' (Кончаловская, URL), так как им не хватает нежности и ласки со стороны своих мужей. Северина рада таким отношениям, потому что Ксавьера для нее - идеальная партнерша: «elle avait la conviction d'avoir recontré sa partenaire» (Schmitt, 2013, c. 307). Ксавьера тоже ощущает себя счастливой рядом с Севериной, она меняется рядом с ней, становится смешливой, ласковой, внимательной: "Lovée contre son amante, elle fuyait une partie d'ellemême pour en rejoinder une nouvelle. Exquise, attentionnée, rieuse, serviable, elle avait déserté son personage de ronchonne» (Schmitt, 2013, c. 307). 'Прижавшись к своей возлюбленной, она как бы освобождалась от части самой себя и становилась другим человеком. С Севериной она была очаровательной, смешливой, ласковой и внимательной, сбросив шкурку вечно недовольной брюзги' (Кончаловская, URL).

В следующей семейной паре измена совершается по обоюдному согласию супругов - Жозефины и Батиста; ее даже нельзя назвать изменой, потому что в их паре появляется третий человек, Изабель, которая в дальнейшем становится членом их семьи. В предыдущих парах была однополая и разнополая измена, тут представлен тройной любовный союз. Жозефина, жена Батиста, подвигла его к этому союзу. Сначала Батист переживал, как это все будет выглядеть, а после знакомства с Изабель успокоился и принял идею жены. В то время как Жозефина, наоборот, с каждым днем стала все больше волноваться и раздражаться, так как начала осознавать, что Батист и Изабель отдаляются от нее, и она может потерять их обоих: «Au fur et à mesure qu'ils se familiarisaient, Joséphine s'inquiétait. Celle qui avait voulu ce trio peinait à l'accepter, percevant d'abord ce que cette experience lui retirait, l'exclusivité de Baptiste, l'exclusivité d'Isabelle. A tout mettre en commun, elle craignait de tout perdre» (Schmitt, 2013, с. 349). 'Когда они стали сходиться ближе, Жозефина заволновалась. Именно она так хотела этого тройственного союза, но теперь ей было трудно с ним смириться; она осознала, что теряет в результате этого опьта: теперь ни Батист, ни Изабель не принадлежали ей полностью. И она 
боялась, что теперь, когда каждый из них принадлежал сразу всем, она потеряет все, что у нее было' (Кончаловская, URL).

B романе Эрика Шмитта к измене прибегают все супружеские пары, так как в измене они находят то, чего им не хватает в спокойной семейной жизни: экстрима, заботы, внимания, иногда и власти.

В произведении Эрика Шмитта есть еще одна молодая семейная пара, которая не имеет детей, Диана и Жан-Ноэль. Данная пара характеризуется следующими отличительными признаками:

- супруги ведут развратный образ жизни;

- для них слова «измена» не существует, супруг спокойно относится к тому, что супругу ласкают другие мужчины.

Анализ описаний первой группы пар в произведении Эрика Шмитта «Попугаи с площади Ареццо» показал, что автор выстраивает дискурс любви следующим образом: он показывает семейные пары, которые отличаются возрастом, социальным статусом, наличием или отсутствием детей, взаимопониманием или отсутствием взаимопонимания между супругами, обязанностями по дому, отношением к совместной жизни, а также мнением по поводу измены.

Во второй группе представлены пары, отношения которых развиваются до заключения брака. Рассмотрим первую пару - Альбану и Квентина, молодых людей, которые сильно любят друг друга. Альбана считает, что любовь - это такое чувство, о котором все знают: "Ça veut dire que nous on le sait et que les autres le savent» (Schmitt, 2013, c. 93). Для Квентина любовь означает быть вместе навсегда: «Selon moi, "être ensemble" ça veut dire plus. Ça veut dire qu'on est amoureux jusqu'au bout» (Schmitt, 2013, с. 93). 'По мне, так «быть вместе» значит гораздо больше. Это значит, что мы любим друг друга до конца' (Кончаловская, URL). Он из-за любви к Альбане поступает учиться в другой город, чтобы она не ревновала его к другим, но по завершению учебы он твердо намерен вернуться к ней. По его словам, детская любовь вечна, хотя взрослые в это не верят: «chez cette race, le male et la femelle fondent dès leur jeunesse un couple qui dure jusqu'à la fin de leur vie <...> Chez les humains, on minimize l'amour des enfants et des adilescents. A chaque fois, les adultes affichent un petit air malin, supérieur, ils entendent sans écouter et regardent sans voir. "Ça ne dure pas"》 (Schmitt, 2013, с. 691-692). 'У попугаев этой породы nары складываются в юности, и они остаются вместе до кониа жизни <...> Люди недооиенивают детскую и подростковую любовь. Взросльее, говоря о ней, делают снисходительный вид, точно они сльшшат, не слушая, и глядят, не видя' (Кончаловская, URL). Он приводит в сравнение жизнь попугаев неразлучников. Квентин их 
сравнивает их отношения со своим отношением к Альбане. В данном случае дискурс любви представлен с помощью речевых актов героев произведения.

Следующая пара - это люди среднего возраста, им около 35 40 лет. Оба партнера имеют детей от предыдущих отношений. Ипполит - обычный садовник с очень привлекательным внешним видом. Патрисия - полная, неухоженная женщина, являющаяся противоположностью Ипполита. Но благодаря смелости Ипполита, который решился признаться в своей любви к ней, Патрисия занялась собой, стала обращать внимание на свою внешность: «elle occupait les heures restantes à maigrir. Comme elle savait qu'elle ne résisterait pas longtemps aux avances d'Hippolyte, sa metamorphose physique virait à l'obsession: elle devait effacer a vache obese aperçue dans la glace. Alors qu'un homme superbe la désirait, elle détestait sn corps; si on lui avait ouvert les portes d'une sale de chirurgie, elle s'y serait précipitée pour qu'on pompe sa graisse, qu'on lui rabote les os du basin, qu'on réduise son estomac à un oeuf de caille, qu'on lui enlève plusieurs mètre d'intestin sous un ventre retendu par le ilomete. Faute de cette solution radical, elle se maltraitait. Au lieu d'entamer un régime, elle s'affamait, se contentant de deux pommes vertes et de trois litres d'eau minérale par jour. Plutôt que de reprendre lentement une activité sportive, elle s'infligeait de marcher des ilometers et avait ressorti de sous son sommier les gadgets sportifs commandés par telephone, envahissant sans vergofne l'appartement avec ses appareils d'abdos-fessiers, ses poids, ses kits de musculation et divers engins de torture» (Schmitt, 2013, с. 162-163). 'А оставшееся время она тратила на борьбу с лишним весом. Зная, что не сможет долго противостоять обаянию Ипполита, она маниакально боролась за свое физическое преображение: нет, она больше не потерпит в своем зеркале тучную корову. С той минуты, как ее полюбил этот красавец, она возненавидела свое тело; она мечтала о ноже хирурга, который откачает ее жир, обстругает тазовые кости, убавит желудок до размеров перепелиного яйиа, удалит лишние метры кишечника и заправит оставшиеся в аккуратно ушитый животик. Но, понимая иллюзорность этих мыслей, она стала измываться над собой. Вместо того, чтобы наладить режим питания и подобрать подходящий комплекс упражнений, она голодала, довольствуясь двумя зелеными яблоками и тремя литрами минеральной воды, изнуряла себя многокилометровой ходьбой и тратила кучу денег на спортивные гаджеты, которые заказывала по телефону и которые теперь бесстыдно наводняли ее квартиру: тут были и тренажеры 
для ягодичных и брюшных мыши, и гантели, и прочие орудия пыток' (Кончаловская, URL).

Дискурс любви данной пары представлен в романе с помощью описания поведения, поступков героев, на которые они были готовы ради любви.

Выше были рассмотрены две пары разнополых партнеров. В романе Эрика Шмитта также присутствует пара однополых партнеров - Том и Натан. Эти двое мужчин любят друг друга. Их отношения складываются не так, как у обычных пар. Том одобряет дерзости со стороны Натана: "Tom sourit. Il n'aurait autorisé personne à lui déverser tant d'insolences; à Nathan, non seulement $\underline{i l}$ pardonnait ses vacheries permanents, mais il les exigeait, comme prevue de sa tendresse» (Schmitt, 2013, с. 143). 'Том ульбнулся. Он никому не позволил бы так ему дерзить, а Натану не только прощал постоянные дерзости, но даже нуждался в них как 6 доказательстве нежной привязанности' (Кончаловская, URL). Том отличается от Натана, и эти его отличия то раздражают, то привлекают: "Ce qui, en Nathan, agaçait Tom l'attirait tout autant. Il adorait et condamnait ses intonations flûtées, son vocabulaire coloré aisément ordurier» (Schmitt, 2013, c. 143-144). 'Черты Натана и раздражали Тома, и одновременно привлекали. Он любил $и$ ненавидел нежные переливы его голоса, его иветистые выражения, подчас непристойные, его рабское следование моде, постоянные изменения прически, пристрастие к модным заведениям и гейклубам' (Кончаловская, URL). Эрик Шмитт описывает следующим образом их дискурс любви: «La monquerie constituait leur madrigal. Parce qu'ils craignaient l'expression traditionnelle de l'amour - sans doute parce qu'ils craignaient l'amour traditionnel -, mimeer le mépris, la raillerie ou la haine les épanouissait, toute rosserie représentant un cadeau. Plus ils se moquaient, plus ils s'avouaient leur affection. Leur sincérité avait besoin de s'habiller de derision pour rester authentique» (Schmitt, 2013, с. 314). 'Подтрунивать друг над другом был их способ объясняться в любви. Они побаивались привычных традиционных признаний, возможно, потому, что побаивались самой традиционной любви, а вот разыгрывать презрение, пренебрежение, даже ненависть - это их освежало, то, что для других гадости, для них было словно подарок. И чем злей они высмеивали друг друга, тем сильнее ощущали, как они близки. Их чувства, чтобы сохранить искренность, должны были облечься в злословие' (Кончаловская, URL). 
Социальное, возрастное, гендерное разнообразие пар является особенностью дискурса любви в романе Эрика Шмитта. Автор показывает, что партнеры готовы совершить неожиданные поступки, чтобы доказать свою любовь. Данный признак является признаком романтического дискурса любви.

Итак, согласно анализу представленных пар в произведении Эрика Шмитта «Попугаи с площади Ареццо», мы выделили основные принципы построения дискурса любви в данном романе:

- многочисленность семейных пар;

- разнообразие семейных пар (отличаются возрастным и социальным статусом, наличием детей, обязанностями по дому, взаимопониманием между супругами и отношением к совместной жизни);

- $\quad$ разнообразие причин и форм измены среди семейных пар (отношение к измене и тип партнера по измене);

- разнообразие любовных отношений до заключения брака (пары отличаются возрастом, разнообразием проявления чувств).

Также следует отметить, что дискурс любви каждой семейной пары противопоставляется дискурсу романтической любви. Каждая пара имеет изъяны в отношениях, от отсутствия взаимопонимания до измены. В семьях имеют место не только межличностные конфликты, но и личностные, которые решаются при помощи измен. Семейные отношения только кажутся благополучными для окружающих. Что касается пар, отношения которых складываются до брака, то данный любовный дискурс содержит признак дискурса романтического: партнеры страдают, идут на жертвы ради любви. Таким образом, роман Эрика Шмитта демонстрирует современный дискурс любви с элементами романтического.

\section{Литература}

Асратян 3.Д. Дискурс художественного произведения // Филологические науки. Вопросы теории и практики. 2015. № 45.

Боротько В.И. Языковой круг: личность, концепты, дискурс. М., 2004.

Велюго О.А. Дискурс любви или любовный дискурс? Комментарий к терминологическому аппарату // Вестник Белорусского государственного экономического университета. 2016. № 1.

Гаврилова Е.В. Разговорный дискурс в художественном тексте и проблема его перевода (на материале современной французской литературы) // Вестник Нижнегородского государственного лингвистического университета им. Н.А. Добролюбова. 2007. № 1. 
Дейк Т.А. ван. Язык. Познание. Коммуникация. М., 1989.

Кибрик А.А. Анализ дискурса в когнитивной перспективе. М., 2003.

Олизько Н.С. Художественный дискурс как полилог автора, читателя и текста // Вестник Челябинского государственного университета. 2011. № 33.

Почепцов Г. Теория коммуникации. М., 2001.

Серио П. Анализ дискурса во Французской школе (дискурс и интердискурс) // Семиотика: антология. М., 2001.

Хабермас Ю. Теория коммуникативного действия // Вестник Московского университета. Серия 7: Философия. 1993. № 4.

\section{Список источников}

Кончаловская Н. Попугаи с площади Ареццо [Электронный ресурс]. URL: https://www.litmir.me/br/?b=232160\&p=1

Schmitt E.-E. Les perroquets de la place d'Arezzo. Paris, 2013.

\section{References}

Asratian Z.D. Diskurs hudojestvennogo proizvedenia [Discourse of Fiction]. Filologicheskie nauki. Voprosi teorii $i$ praktiki [Philological Science. Theory and Practice Issues]. 2015. No. 4.

Borot'ko V.I. Yazikovoi krug: lichnost', konsepti, diskurs [Language Circle: Personality, Concepts, Discourse]. Moskva, 2004.

Velugo O.A. Diskurs lubvi ili lubovniy diskurs? Kommentariy k termenologicheskomu apparatu [The Discourse of Love or a Love Discourse? Comment to the Terminological Apparatus]. Vestnik Belorusskogo gosudarstvenogo ekonomicheskogo universiteta [Bulletin of Belarus State Economical University]. 2016. No. 1.

Gavrilova E.V. Razgovorniy diskurs v hudojestvenom texte i problema ego perevoda (na materiale sovremennoy francuzkoy literaturi). [Colloquial Discourse in a Literary Text and the Problem of Its Translation (by the material of modern French literature)]. Vestnik Nijnegorodskogo gosudarstvenogo lingvisticheskogo universiteta im. N.A. Dobrolubova [Bulletin of Nizhiy Novgorod State Lingvistic Univesity]. 2007. No. 1.

Deyk T.A. van Yazik. Poznanie. Kommunikaciya [Language. Knowledge. Communication]. Moskva, 1989.

Kibrik A.A. Analiz diskursa v kognitivnoy perspektive [Discourse Analysis in Cognitive Perspective]. Moskva, 2003.

Oliz'ko N.S. Hudojestveniy diskurs kak polilog avtora, chitatelay i texta [Artistic Discourse as a Polylogue of the Author, Reader and Text]. Vestnik Chelaybinskovo gosudarstvenogo universiteta [Bulletin of Chelaybinsk State Univesity]. 2001. No. 33.

Pochepcov G. Teoria kommukacii [Communication Theory]. Moskva, 2001.

Serio P. Analiz diskursa vo Phrancuzskoy shkole (diskurs I interdiskurs) [Analysis of Discourse in the French School (discourse and interdiscourse)]. Semiotika: antologia [Semiotics: an anthology]. Moskva, 2001.

Habermas U. Teoria kommunikativnogo deystvia [Theory of Communicative Action]. Vestnik Moskovskogo universiteta [Bulletin of Moscow Univesity]. Iss.7: Philosophiya. 1993. No. 4. 


\section{List of sources}

Kolchalovskaya N. Popugai s ploshadi Areco [Parrots from the Square of Arezzo].URL: https://www.litmir.me/br/?b=232160\&p=1

Schmitt E.-E. Les perroquets de la place d'Arezzo. Paris, 2013.

\section{АНАЛОГИИ В СЮЖЕТНЫХ МОТИВАХ ЯКУТСКОГО ОЛОНХО И ХАКАССКОГО АЛЫПТЫХ НЫМАХ ${ }^{1}$}

\section{А.Ф. Корякина}

Ключевые слова: эпос, олонхо, алыптых нымах, сравнительный анализ, сюжетные мотивы, девушки-богатырки. Keywords: epic, olonkho, alyptykh nymah, comparative analysis, plot motifs, girl-heroes.

\section{DOI 10.14258/filichel(2019)3-11}

Сравнительное изучение эпических традиций тюрко-монгольских народов с давних времен привлекало внимание фольклористов, фундаментальные исследования которых доказывают присутствие взаимосвязей в жанре, тематике, сюжетно-композиционной и образной системе, стиле изложения, в поэтическом языке эпосов генетически родственных народов.

В статье ведется сравнительно-типологическое исследование древних сюжетных мотивов якутского олонхо и хакасского алыптых нымах. Актуальность сравнительно-типологического сравнения была указана Б.Н. Путиловым: «<..> историческое изучение фольклора $<\ldots>$ невозможно без самого широкого и систематического сравнительного анализа, $<\ldots>$ без выявления и изучения фактов повторяемости, в конечном счете - без установления общих закономерностей и общих особенностей» [Путилов, 1976, с. 3]. Принимая утверждение крупного ученого за основу своего исследования, мы ставим цель - выявление сходств и особенностей мотивов якутского олонхо и хакасского алыптых нымах.

\footnotetext{
${ }^{1}$ Исследование выполнено при финансовой поддержке НИП СВФУ «Героические эпосы тюрко-монгольских народов Евразии: проблемы и перспективы сравнительного изучения» (2018-2021).
} 